\section{California split}

Voters in California rejected, by a margin of two to one, a proposition which would seriously have impededand possibly have halted-the use of nuclear power in California. The outcome was greatly influenced by the last-minute approval of three nuclear safety bills spawned by the debate over the proposition. Governor Edmund Brown signed them into law a few

Do research workers know why they choose a particular subject to study? Today there are those who say that they have no right to make such a choice. It is suggested that they should rely on some "customer", backed by a committee or other collection of wise men, coming forward and telling them what they should do, and even how they should do it. While the working of this system can hardly be said to have contributed to scientific productivity, it is perhaps timely to look at the way in which those who have had the choice have exercised it. Has it generally given better results?

Several times in my career I have been fortunate enough to be able to choose my own research problems. During the 1939-45 War I was adequately supported by a rather unrestriative research fellowship, while I was temporarily barred from military service by the register of reserved occupations. I felt that my somewhat academic studies in insect physiology had little relevance to the war, so I searched for a more practical problem. Having contacts with medical entomology, I soon found that the parasitic disease scabies, or "the itch", was causing increasing concern. Soldiers as well as civilians were suffering and were immobilised by treatment. It was also feared that any breakdown in national hygiene following enemy bombing might precipitate an uncontrollable epidemic. The disease was caused by the tiny mite, Sarcoptes, burrowing into the skin, and it was clear that a better knowledge of its biology was needed. I have, until recently, assumed that I decided to work on scabies for humanitarian and patriotic reasons; now I am beginning to re-examine my matives.

A later opportunity for choice occurred some ten years ago, when I was director of a research station. Provided that the station ran fairly smoothly, the staff got on with their work, and I showed up at an adequate number of committee meetings, no one objected if I did a little research in the remainder of my days before the vote, a fact which enabled him to demonstrate his concern for safety without the risk of alienating voters by coming out in favour of the proposition.

\section{No visit from USSR}

Academician Yakov Zeldovich, winner of three Lenin Prizes and one Stalin (now State) prize for physics, was unable to attend a ceremony at Cambridge last week at which he was to

time. There would have been difficulties if I had chosen an expensive field and asked for a lot of money for equipment, but I needed to show that my view that good work could be done cheaply had some foundation. So I decided to work on the mole, Talpa europeanea. At the time I believed that I made this choice because I thought that the mole

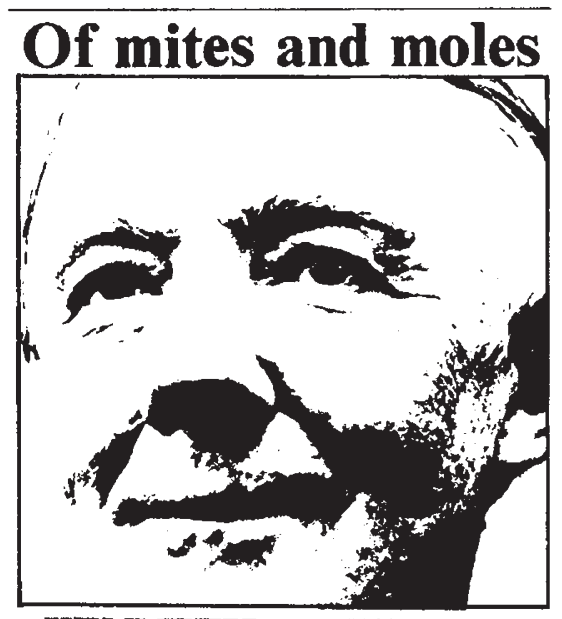

KENNETH MELLANBY

could be a simple indicator of the potential fertility of the land it infested. Text books told us that moles were very voracious, eating twice their own weight of earthworms daily. As worms abound in largest numbers in fertile soil, I hoped that a count of molehills could suggest whether the ground was or was not worth cultivating. Unfortunately many of the well-known "facts" about moles proved to be wrong, their appetite had been overestimated, and the largest number of hills sometimes appeared in the poorest soil. The mole cannot be used to indicate fertility, but it is still a fascinating creature.

Recently, I have found myself once more involved with these two problems, scabies and the mole. At first sight they appear to have little in common, one concerning a medical pest, the other a minor pest of agriculture. I have just returned from a conference on scabies in Minneapolis sponsored by the American receive an honorary DSc degree. There is speculation that the Soviet authorities refused him a visa for security reasons. Yet earlier in his career Academician Zeldovich was closely connected with defence work, including research into the physics of conventional and nuclear explosions, but was not prevented from visiting London in 1965 to attend the Fourth International Conference on Relativity and Gravitation.

Medical Association, the American Academy of Dermatology and other bodies. In order to give three lectures on the biology of the Sarcoptes I had to re-read my publications of over 30 years ago and check the results with recent observations. It was gratifying to find that the subject had remained virtually unchanged for this period. At about the same time as I was setting off for America a children's book which I had just written on the life of a mole appeared. I found myself comparing these two apparently very different creatures.

The itch mite is a tiny eight-legged arthropod, the mole is a warmblooded mammal. Their main resemblance is that they both burrow, the itch mite in the human skin, the mole in the soil which could be described as the world's epidermis. The mite's burrowing causes a disease of the skin; gardeners whose lawns have suffered may think the mole gives rise to similar symptoms. But the burrowing mode of life can cause remarkable similarities in very different creatures. Both mites and moles are solitary, remaining in their tunnels for all or most of their lives. Both feed in the burrow. The young are born in the burrows, and then migrate out and eventually start their own tunnels. The males are more mobile than the females, they actively search for mates, but they separate again after oopulation.

Having made this comparison, I began to examine my original motivation. Were the admirable and socially acceptable reasons I originally put forward for these studies the correct ones? Or have I some deep seated psychological urge to study the phenomenon of burrowing? In my case both investigations were reasonably productive. Should all soientists undergo psychological examinations, to fit their problems to their subconscious predilections? Perhaps research workers, to be successful, need to deceive themselves regarding their real reasons for choosing a subject, as well as those who they approach for financial suppont for their investigations. 